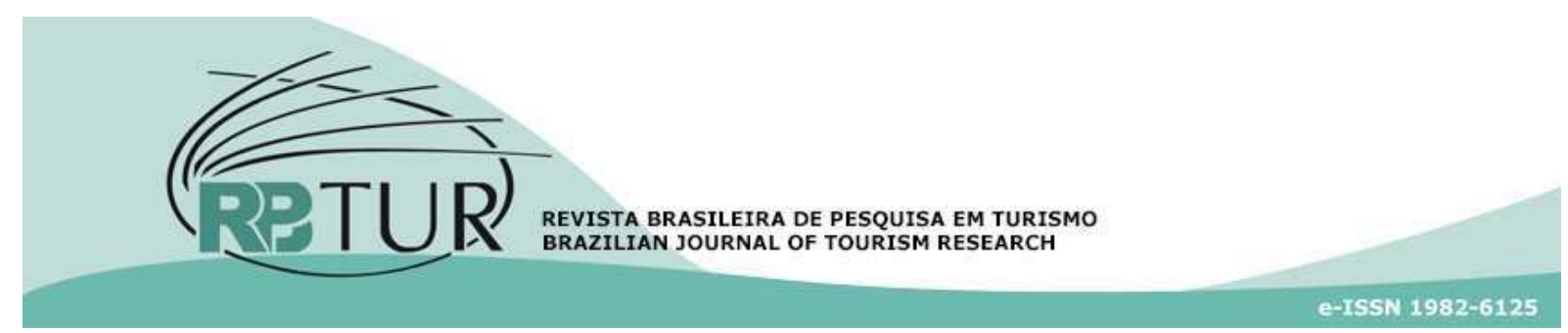

DOI: $\quad$ http://dx.doi.org/10.7784/rbtur.v12i2.1357

\title{
Da lógica ao lucro: uma reflexão sobre a aplicabilidade da lógica dominada por serviço ao ramo hoteleiro
}

\section{From logic to profit: a reflection on the applicability of service- dominant logic to the hotel industry}

\section{De la lógica al lucro: una reflexión sobre la aplicabilidad de la lógica dominada por servicio al sector hotelero}

\author{
Jefferson Oliveira da Silva-Lacerda ${ }^{1}$ \\ Marcela Nunes de Castro ${ }^{2}$ \\ Ricardo Teixeira Veiga ${ }^{3}$
}

Resumo: A Lógica Dominada por Serviço (LDS) obteve importância na ciência de marketing por oferecer uma perspectiva alternativa para a compreensão das trocas sociais e econômicas. Para tanto, o estudo dos sistemas econômicos é redirecionado de um foco centrado tão somente na materialidade do produto para outra lógica, pós-materialista, em que os recursos operantes são essenciais e o serviço é trocado por serviço. Este ensaio científico pretende elucidar, mediante uma reflexão, os principais pontos levantados na LDS, considerando especialmente o conceito de ecossistema de serviço, e avaliando/propondo a aplicação dos conceitos da LDS ao ramo de hotelaria. Uma das proposições da LDS aplicáveis às empresas hoteleiras diz respeito à cocriação de valor, em que hóspedes são tratados como cocriadores. A cocriação de valor resulta da integração de recursos de múltiplos atores em suas interações, tanto nas trocas diretas quanto indiretas.

Palavras-chave: Lógica Dominada por Serviço (LDS). Ecossistema de Serviço. Gestão de hotéis.

${ }^{1}$ Universidade Federal de Minas Gerais (UFMG). Definição de tema do ensaio, elaboração da primeira versão, escrita de capítulo sobre a Lógica Dominada por Serviço, resposta aos revisores, elaboração do resumo em espanhol, revisão ortográfica e das normas de formatação. Agradecimento ao CNPq pela bolsa de doutorado.

2 Universidade Federal de Minas Gerais (UFMG). Pesquisa bibliográfica, elaboração do resumo, revisão da primeira versão, ajustes de estilo e normalização.

${ }^{3}$ Universidade Federal de Minas Gerais (UFMG). Complemento da pesquisa bibliográfica, escrita de capítulo sobre a Lógica Dominada por Serviço, extensão e refinamento de capítulos sobre aplicação da LDS no setor hoteleiro e considerações finais, tradução para o inglês. Agradecimento ao CNPq pela bolsa de produtividade em pesquisa.

Artigo recebido em: 14/09/2017. Artigo aceito em: 13/04/2018. 
Abstract: The Service-Dominant logic (S-D logic) has gained importance in Marketing Science for offering an alternative perspective on the understanding of social and economic exchanges. For this, the study of economic systems is redirected from a materialistic focus to a post-materialistic one in which operant resources are essential, and service is exchanged for service. This scientific essay intends to elucidate, through pondering, the main issues raised by S-D logic, especially taking account the service ecosystem concept and evaluating/proposing the application of the S-D logic concepts to hotels. One of the S-D logic's propositions that can be applicable to hotels is the one concerning value co-creation - in which guests are treated as cocreators. Value co-creation results from resources integration from multiple actors in their interactions, both in direct and indirect ex-changes.

Keywords: The Service-Dominant Logic (S-D Logic). Service Ecosystem. Hotel Management.

Resumen: La Lógica Dominada por Servicio (LDS) obtuvo importancia en la ciencia de marketing por ofrecer una perspectiva alternativa para la comprensión de los intercambios sociales y económicos. Por lo tanto, el estudio de los sistemas económicos es redireccionado de una perspectiva centrada tan sólo en la materialidad del producto hacia otra lógica, postmaterialista, en que los recursos operantes son esenciales y el servicio es cambiado por servicio. Este ensayo científico pretende aclarar, mediante una reflexión, los principales puntos señalados en la LDS, considerando especialmente el concepto de ecosistema de servicio, y evaluando/proponiendo la aplicación de los conceptos de la LDS al sector hotelero. Una de las proposiciones de la LDS aplicables a las empresas hoteleras se refiere a la cocreación de valor, en la que los huéspedes son tratados como cocreadores. La cocreación de valor resulta de la integración de recursos de múltiples actores en sus interacciones, tanto en los intercambios directos como indirectos.

Palabras clave: Lógica Dominada por Servicio (LDS). Ecosistema de Servicio. Administración Hotelera.

\section{INTRODUÇÃO}

O ensaio tem como base as ideias advogadas por Stephen Vargo e Robert Lusch no artigo 'Evolving to a New Dominant Logic for Marketing', de 2004 do Journal of Marketing. Nesse trabalho, os autores visam esclarecer a evolução do pensamento de marketing em direção a uma lógica emergente para os fenômenos de troca. A partir dessa seminal contribuição, os autores e inúmeros outros acadêmicos vêm realizando pesquisas sob a nova perspectiva. Como resultado dos estudos, Vargo e Lusch editaram no mesmo ano o livro 'The Service-Dominant Logic of Marketing: dialog, debate, and directions', compilando contribuições de emitentes acadêmicos de marketing, tais como, Shelby Hunt, Philip Kotler, Evert Gummesson e Richard Oliver.
Após dez anos de constantes avanços e debates, em 2014, Lusch e Vargo lançaram o livro 'Service-dominant logic: premises, perspectives, possibilities', cujo objetivo foi consolidar o progresso teórico, acrescentar novas perspectivas e também contribuir para o ampla disseminação de suas ideias sobre o que eles entendem ser um novo paradigma de trocas sociais e econômicas, que deve superar a tradicional lógica dominada por produtos (LDP).

A LDP estabelece que a produção e troca de bens são os pilares da economia e dos negócios, definindo o propósito da firma e a função da troca econômica em termos da fabricação e distribuição de produtos - principalmente tangíveis. Segundo a LDP, a firma é o ator proativo, aquele que é o inovador, desenvolvedor, produtor, distribuidor e promotor de bens, é uma entidade fechada, 
cujo propósito é produzir e vender bens que tenham determinado valor para mercados existentes, que agregam consumidores com demandas.

Em contraposição, Vargo e Lusch advogam uma nova lógica, dominada por serviço, termo que deve ser entendido como a aplicação de competências, habilidades e outros recursos, em benefício dos atores envolvidos nas interações. De acordo com a lógica S-D, conhecimento, informação, habilidades e outros recursos ativos ou operacionais são os principais determinantes de valor.

Os hotéis são empresas de serviços múltiplos, cujo resultado final para os clientes depende da infraestrutura física, dos sistemas de informação, e, sobretudo, das competências e conhecimentos dos funcionários e de sua disposição de servir. Devido à natureza de um hotel e às dificuldades em suas operações e gerenciamento, nós pretendemos avaliar neste ensaio se as premissas fundamentais da LDS podem ser aplicadas a este tipo de organização.

Ritzer (2015) traz à hospitalidade o conceito de "prossumerismo", que significa a combinação de produção e consumo. Por exemplo, na internet, leitores de blogs também produzem conteúdo. Sob o conceito de prossumerismo, os usuários podem participar proativamente do design e da produção de serviços que eles mesmos consomem, agindo ao mesmo tempo como produtores colaborativos e consumidores, no sentido de coprodução do trabalho e cocriação de valor.

Recentemente, a LDS tem sido usada como moldura teórica para estudos na indústria hoteleira e turismo em geral. Com base na premissa da LDS de que o valor do serviço é sempre cocriado pelos atores, Morosan \& DeFranco (2016) usam dados de uma amostra geral de clientes de hotéis nos Estados Unidos para desenvolver e validar empiricamente um modelo conceitual que reconhece a importância central da contribuição dos clientes na cocriação de valor de experiências de serviço usando dispositivos móveis.

FitzPatrick, Davey, Muller e Davey (2013) aplicam a LDS para descortinar os fundamentos do capital intelectual na indústria hoteleira. Os autores recomendam maior conscientização sobre as bases da criação de valor, indo além do mero reconhecimento da importância do valor de marca. Segundo os autores, essa abertura conceitual é possível através do desenvolvimento de construtos sofisticados para a efetiva gestão de ativos intangíveis, adotando-se a LDS como moldura teórica.

Usando a LDS, Cabiddu, Lui e Piccoli (2013) examinam como a tecnologia de informação (TI) viabiliza a cocriação de valor no turismo e por que alguns atores aparentemente se apropriam mais do valor cocriado em suas parcerias, atribuindo esse resultado a seu superior ajuste estratégico em relação aos objetivos das iniciativas de cocriação, sinergia com outros atores do ecossistema de serviço e prontidão para uso da TI na condução eletrônica dos negócios.

Para que o potencial de aplicação da Lógica Dominada por Serviço no turismo seja mais bem compreendido, é necessário apresentar seus fundamentos, o que é feito na próxima seção. 


\section{INTRODUÇÃO À LÓGICA DOMINADA POR SERVIÇO (LDS)}

Tratada por Achrol e Kotler (2012) como parte ou subfenômeno do marketing (experiências de clientes), a Lógica Dominada por Serviço (LDS) consiste em uma ótica alternativa para compreensão do mundo das trocas sociais e econômicas entre atores humanos, tanto individualmente quanto em grupos. Os líderes desta nova linha de pensamento, Stephen Vargo e Robert Lusch, advogam uma nova perspectiva ou uma visão alternativa à Lógica Dominada por Produtos (LDP), a lógica institucional corrente.

A partir da desconstrução da dicotomia de produtor e consumidor - agora compreendidos como atores - e da visão linear de cadeias produtivas, Vargo e Lusch (2014) analisam os sistemas sociais e econômicos enquanto ambientes colaborativos nos quais os atores cocriam valor a partir da integração de recursos diversos nos processos de troca de serviço por serviço.

Há dois componentes de cocriação. $O$ mais abrangente deles é a cocriação de valor, em que os autores mobilizam e integram recursos, gerando resultados, cujo significado e importância são singulares para cada ator. O segundo componente da cocriação é o que pode ser chamado de coprodução, e pode ocorrer por meio de inovação compartiIhada, codesign ou de partilha de produção de bens relacionados, e podem ocorrer com os atores ou com os outros parceiros da rede. Estas interações e/ou redes desempenham um papel central na criação de valor e de troca, por isso a LDS vê o marketing como processos sociais e econômicos (Lusch \& Vargo, 2006).

Com uma perspectiva um pouco diferente, Grönroos e Voima (2013) avaliam o processo de cocriação de valor em esferas distintas (a esfera do produtor, a esfera conjunta e a esfera do consumidor) e abordam a importância de otimizar e combinar recursos operados e operantes disponíveis para a firma, de modo que ela consiga oferecer aos consumidores o maior valor possível, tanto na esfera conjunta quanto na esfera do consumidor.

$\mathrm{Na}$ Lógica Dominada por Produtos (LDP) os serviços são produtos intangíveis em uma relação de troca. Operações e marketing de serviço envolvem dificuldades derivadas dos fatores IHIP (Zeithaml, 1981), um acrônimo para intangibilidade, heterogeneidade, inseparabilidade e perecibilidade.

No que se refere à intangibilidade, seguindo o paradigma tradicional da LDP, o valor é definido pelo prestador do serviço e depende diretamente da produtividade nas operações. Na LDS, o valor é intangível, experiencial e cocriado pelos atores envolvidos. No tocante à heterogeneidade, na LDP os bens podem ser feitos para obterem vantagens na padronização do sistema operacional e nos ganhos de eficiência da produção em massa. Já na LDS, cada ator é único, tal que a heterogeneidade e as ofertas personalizadas são comuns (Lusch \& Vargo, 2014).

Relativamente à inseparabilidade, enquanto a LDP preconiza a separação entre firmas e clientes para alcançar a máxima produtividade, na LDS a interação entre os atores aumenta a efetividade nas ofertas de serviço, tendo em vista que o valor é resul- 
tado de cocriação. Finalmente, na visão da LDP, os bens são tão perecíveis quanto os serviços. Assim, como os contextos de cocriação de valor são variáveis e dinâmicos, as experiências são igualmente perecíveis, porém podem ser lembradas e compartidas.

Como explicado anteriormente na introdução, na nova lógica, a definição de "serviço" (no singular) refere-se ao processo de realização de algo em benefício da outra parte, como fruto da união dos atores que fazem trocas e que têm, como seus fundamentos de motivação, os intercâmbios econômicos e sociais (Vargo \& Lusch, 2014). No contexto da LDS, serviços e mercadorias são mecanismos de distribuição de valores, e serviço não deve ser, como usualmente, interpretado como bem intangível.

Outra questão discutida na lógica S-D é a relação entre o valor de uso e o valor de troca. O valor de uso é definido segundo o ator beneficiado, que determina o valor no momento da experiência e cocriação de valor. Por outro lado, o valor de troca é um conceito econômico que não traduz o benefício conseguido com o consumo de determinado serviço, pois se baseia no valor como utilidade, criada pelo provedor. Assim, o valor de troca é também interpretado como mecanismo de troca de serviço por direitos a obtenções de serviço ("direitos de obtenção de serviço") em futuras trocas (Lusch \& Vargo, 2014).

Portanto, uma organização não garante que seu mercado-alvo obterá um produto ou serviço com algum valor agregado, que resultou de seu processo de produção, extração ou entrega. De fato, as propostas de valor são oferecidas como convites para um ator que busca benefícios se engajem com o provedor. Uma proposição de valor não é elaborada apenas por uma empresa. Ao contrário, resulta da cooperação de uma comunidade de outros atores, tais como, seus fornecedores, distribuidores e até agências governamentais, que integram recursos e os levam ao mercado para serem integrados novamente (Vargo \& Lusch, 2014).

Os recursos são classificados como operados e operantes (Lusch e Vargo, 2014). Recursos operados são geralmente estáticos e precisam sofrer uma ação antes que possam gerar valor. Por outro lado, recursos operantes são capazes de transformar os recursos operados para obter os efeitos pretendido. Como a LDS pressupõe a especialização e aplicação de habilidades e competências em benefício próprio ou de outro (Lusch e Vargo, 2004), os recursos operantes assumem um papel essencial em toda construção de valor, possibilitando que os seres humanos expandam o estoque útil de recursos operados naturais.

Após anos de debates com acadêmicos e profissionais, Lusch e Vargo (2014) estabeleceram um léxico com quatro axiomas e seis premissas fundacionais derivadas para encapsular a estrutura da LDS. Mais recentemente, Vargo e Lusch (2016) acrescentaram mais uma premissa, a décima primeira, que consideram como o quinto axioma. Axiomas e premissas são enumerados e explicados a seguir:

Primeiro axioma e primeira premissa fundacional: "O serviço é a base fundamental da troca". Atores levam ao mercado suas habilidades mentais e físicas - recursos operantes - e essas estão distribuídas de forma 
não homogênea na população, de forma que os atores não dispõem de todos os recursos necessários para tornar seu sistema viável. Dada a especialização dos atores na provisão de serviços específicos, a troca de serviço por serviço é essencial para a viabilidade do sistema de trocas considerado (Lusch \& Vargo, 2014).

Segunda premissa fundacional: "A troca indireta mascara a base fundamental da troca". Quando um ator não interage diretamente com o outro ao qual está servindo, ouvir a voz do beneficiário é ainda mais complexo. As trocas de serviço por serviço podem ser mascaradas por trocas em que o que um dos atores oferece é pagamento de um valor monetário recebido, recebendo como contrapartida produtos ou serviços. O processo fundamental, todavia, não é alterado. Os atores ainda assim trocam habilidades coletivas ou individuais pelas de outros atores, tal que dinheiro, produtos e serviços são apenas os veículos ou intermediários (Lusch \& Vargo, 2014).

Terceira premissa fundacional: "Produtos são mecanismos de distribuição para a provisão de serviço". Produtos são veículos que possibilitam a troca de serviço(s) e funcionam como mecanismos de distribuição de habilidades aplicadas na medida em que os atores envolvidos no processo de produção possuem conhecimentos que podem ser transformados em bens (Lusch \& Vargo, 2014). Por exemplo, um remédio é veículo de entrega de um serviço terapêutico e, como 'serviço', o remédio integra conhecimentos farmacológicos e biotecnologia (recursos operantes).

Quarta premissa fundacional: “Re- cursos operantes são as principais fontes de vantagem competitiva". Matérias-primas, instrumentos e outros recursos operados são estáticos e passivos, pois são processados por recursos operantes, tais como, conhecimento e habilidades humanas. Sendo assim, apenas os atores proprietários dos recursos operantes podem obter vantagens competitivas duradouras (Lusch \&Vargo, 2014).

\section{Quinta premissa fundacional:}

"Todas as economias são economias de serviço". O processo fundamental de troca econômica refere-se à aplicação de habilidades físicas e mentais na provisão de serviço. Serviço e recursos operantes são a essência das atividades econômicas, e como todas as trocas são, em última instância, troca de serviço por serviço, todas as economias são, na verdade, economias de serviço. Logo, é superada a classificação tradicional da economia nos setores primário, secundário e terciário (Lusch\& Vargo, 2014).

Segundo axioma e sexta premissa fundacional: "O cliente é sempre cocriador de valor". Este axioma supera o conceito de valor adicionado, que afirma que o valor é incorporado durante os processos de produção, distribuição e marketing do produto, sem o envolvimento do consumidor. No pensamento centrado em serviço, os produtos são meio de prestação de serviço, que gera valor. Logo, o beneficiário continua o processo de produção de valor no momento do uso do produto e na integração deste com outros recursos. A compreensão desse axioma é facilitada quando o termo A2A ("Actor to Actor") é adotado a necessidade 
de interação dos atores, para melhorar a viabilidade de seus sistemas, é compreendida adequadamente. Para tanto, seres humanos se organizam em redes com o propósito de conectar a recursos que irão conectálos a outros indivíduos e recursos (Lusch \& Vargo, 2014).

Sétima premissa fundacional: "A empresa não pode entregar valor, mas, sim, oferecer proposições de valor". Conforme previamente explicitado, uma empresa pode oferecer uma promessa que pode ser cumprida mediante interação dela com seu beneficiário, podendo o valor daquela oferta ser aumentado ou subutilizado pelo usuário, a depender da maneira que ele integra seus recursos (Lusch \& Vargo, 2014).

Oitava premissa fundacional: "Uma visão centrada no serviço é inerentemente orientada ao cliente e relacional". A natureza da cocriação também é relacional uma vez que atividades de troca entre atores combinam independente e interativamente ao longo do tempo para cocriar valor. A visão centrada no serviço é intrinsecamente orientada para o cliente e tem um caráter relacional. Na LDP promove-se a orientação ao cliente através do gerenciamento de relacionamento (CRM), ou seja, não há uma reorientação ao cliente. Mas, como a LDS foca a cocriação de valor pelos atores, o relacionamento entre eles não é opcional, porque mesmo quando não há uma transação econômica, ainda assim existe um relacionamento. Na orientação de serviço o relacionamento é com o beneficiário do serviço (Lusch \& Vargo, 2014).

Terceiro axioma e nona premissa fundacional: "Todos os atores econômicos e sociais são integradores de recursos". De acordo com a LDS, os atores tentam aumentar a viabilidade de seus sistemas através da troca e da integração de recursos, sejam eles de mercado, públicos ou privados. Os atores excedem a troca imediata de serviço e criam redes e recursos para cocriar valor.

Quarto axioma e décima premissa fundacional: “O valor é único e fenomenologicamente determinado pelo beneficiário". Em cada caso, valor emerge num contexto distinto, envolvendo a disponibilidade, integração e uso de uma combinação peculiar de recursos e atores (Lusch \& Vargo, 2014).

Essa integração e combinação de recursos, para cada um dos atores, manifestam-se como um senso de valor e de satisfação com sua vivência.

Quinto axioma e décima primeira premissa fundacional: "A cocriação de valor é coordenada por instituições e arranjos institucionais criados pelos atores". As instituições constituem as bases para a cooperação e coordenação nos ecossistemas de serviço, possibilitando e potencializando as trocas, cocriação de valor e integração de recursos. Exemplos de instituições fundamentais: leis, sistema monetário, protocolos de comunicação, padrões de qualidade e de segurança etc.

\subsection{A Abordagem de Ecossistemas de Ser- viço}

Os processos são criados por atores para produzir resultados favoráveis. No entanto, esses resultados não são os mesmos para cada ator, porque cada um interpreta o valor resultante de maneira distinta, 
conforme sua própria perspectiva de investimentos e resultados. Assim, essencialmente ecossistemas são uma série de processos, considerados em torno de uma comunidade de interesse (Lusch \& Vargo, 2014). Tanto nos ecossistemas organizacionais quanto nos ecossistemas biológicos, processos e funções são regidos por uma hierarquia. Espécies e organizações são semelhantes na medida em que ambos os grupos são compostos por atores e estão relacionados a outros grupos dentro do mesmo ecossistema, em uma rede complexa entre organizações (Mars, Bronstein, \& Lusch, 2012).

Portanto, os ecossistemas contemplam redes de atores interconectados que dependem uns dos outros para sobreviver. Porém, a interdependência entre dois atores pode ser indireta (Lusch \& Vargo, 2014). Mars, Bronstein e Lusch (2012) comparam ecossistemas biológicos e organizacionais, apontando suas semelhanças e diferenças. A noção de ecossistema organizacional funciona como uma metáfora útil para esclarecer os sistemas de uma rede e as intrigantes funções da rotina de organizações complexas, como hospitais, empresas e escolas. Apesar da fertilidade da interpretação das organizações e de suas relações como ecossistemas, os autores advertem os gestores a não tomarem essa analogia como se fosse perfeita, já que os ecossistemas biológicos têm idiossincrasias que não têm paralelo nos ecossistemas organizacionais.

Deve-se ressaltar que os ecossistemas organizacionais são dinâmicos, de modo que as empresas que não evoluem para o bem-estar social geral são fortes can- didatos a se tornarem obsoletas e a serem suprimidas. Mas, na verdade, as consequências da competição são distintas em diferentes ecossistemas. Enquanto nos ecossistemas biológicos a competição é sempre prejudicial para todas as espécies envolvidas, nos ecossistemas organizacionais ela pode ser benéfica ou prejudicial dependendo das circunstâncias (Mars, Bronstein, \& Lusch 2012). Por exemplo, Hunt (1999) afirma que a competição entre empresas é um processo evolutivo, gerador de desequilíbrio, que é movido pela inovação endógena. No entanto, no futuro, novas lógicas institucionais tornarão as intervenções ambientais cada vez mais explícitas e orientadas para as relações ganha-ganha de atores e ecossistemas (Lusch \& Vargo 2014), porque em relacionamentos de longo prazo, as estratégias de co-operação tendem a valer mais a pena para os atores do que as estratégias oportunistas, que buscam a maximização dos ganhos individuais (Axelrod, 1984).

O conceito de "ecossistemas de serviço" foi introduzido por Vargo \& Lusch (2014). São sistemas autoajustados de integração de recursos dos atores, conectados por lógicas institucionais e cocriação de valor, através de trocas de serviço. Logo, normas e instituições são necessárias ao processo de cocriação de valor, afetando e orientando como um indivíduo se comporta e estabelece relações. Ao mesmo tempo, as normas e instituições sociais são construídas a partir das práticas de mercado dos agentes, seguindo o conceito de estruturação, e dependem da maneira como os atores agrupam os recursos disponíveis no 
ecossistema em que realizam as trocas (Vargo \& Akaka, 2012).

Dentre as características peculiares dos ecossistemas de serviços, podemos distinguir: 1) o serviço está associado à aplicação do conhecimento e das competências de um ator em benefício do outro; 2) os recursos operantes são os que podem atuar em outros recursos para criar valor, e o valor é criado pelos esforços de colaboração entre firmas, consumidores e outros atores; 3) esse valor é situacional na medida em que diferentes contextos culturais (práticas e rotinas) podem refletir experiências únicas; 4) os ecossistemas de serviços podem ser vistos sob três distintas dimensões de interação - o nível micro entre empresa e consumidor, o contexto meso envolvendo atores adicionais e um conjunto especial de instituições, e, finalmente, o nível macro de sistemas mais estáveis, como conhecimento compartilhado, instituições e regras duradouras (Akaka, Vargo, \& Lusch, 2013; Lusch \& Vargo 2014).

Vargo e Akaka (2012) destacam a importância da ampliação da perspectiva da criação de valor a partir da teoria da estruturação, sistemas e ecossistemas de serviços, pois esses fatores são fundamentais no processo de cocriação de valor. Os autores também chamam a atenção para a importância das instituições sociais na maneira como elas afetam o comportamento dos indivíduos. Ademais, as trocas podem ocorrer no contexto cultural e, por conseguinte, podem ser consideradas mais como um arranjo social ou político, uma vez que são um processo econômico orientado tanto por instituições econômicas quanto por instituições não econômicas (Mars, Bronstein, \& Lusch, 2012).

Nesse sentido, o conceito de "valor no contexto cultural", proposto por Akaka, Vargo e Lusch (2013), amplia a perspectiva do contexto social e inclui sinais e símbolos que influenciam (ou são influenciados por) interações e trocas. $\mathrm{O}$ uso desse constructo fomenta uma perspectiva cultural mais dinâmica do que as estruturas tradicionais. As- sim, a complexidade de contextos internacionais é baseada tanto no aumento de ações no nível micro quanto de interações entre instituições nos níveis meso e macro.

A Aplicação da Lógica Dominada por Ser- viço no Ramo Hoteleiro Em mercados cada vez mais competitivos, alguns gestores hoteleiros já se mostram dispostos a implantar estratégias que visem o aumento do bem-estar geral dos funcionários, a sua produtividade e, consequentemente, o sucesso da organização (Castelli, 2003). De fato, as empresas hoteleiras estão reinventando formas de administrar seus negócios, revendo padrões antigos e adequando-os às necessidades exigidas pelo ambiente, na busca pela competitividade.

Mars, Bronstein e Lusch (2012) criaram uma metáfora para as organizações, enxergando-as como ecossistemas. Assim, tal como nos ecossistemas biológicos em que a interligação das espécies leva à sua interdependência, os setores ou funções de um hotel - controle de reservas, recepção, limpeza de quarto, restaurante, almoxarifado etc. - são inter-relacionados e conectados, embora sua relação não seja às vezes óbvia ou direta. Nos ecossistemas biológicos, pode-se observar que as espécies se 
submetem a uma hierarquia predatória, isto é, presa e predador possuem relações ecológicas interespecíficas e intraespecíficas. No contexto organizacional da indústria hoteleira, cada departamento tem um chefe, ou seja, alguém que é responsável por ele e tem subordinados e eventuais colaboradores em outros departamentos, emulando o que na biologia é chamado de relações interespecíficas e intraespecíficas, no caso de envolver respectivamente indivíduos de diferentes espécies ou da mesma espécie. Além disso, sabe-se que todos os trabalhadores em um hotel, incluindo os chefes dos departamentos, estão sob a autoridade do seu gerente geral. Assim, espécies e organizações são semelhantes, uma vez que ambos os grupos compreendem atores e estão conectados a outros grupos em um ecossistema comum, originando fortes laços entre as organizações (Mars, Bronstein, \& Lusch, 2012).

Outro ponto importante que demanda atenção é a existência de funções específicas. Como nos ecossistemas biológicos, cada departamento de uma empresa hoteleira tem uma função peculiar, mas não isolada. É importante observar que, no ambiente ecológico, quando uma espécie se extingue, toda a sua cadeia alimentar pode ser afetada, desequilibrando o ecossistema (Mars, Bronstein, \& Lusch, 2012). Assim, qualquer departamento ineficaz de um hotel pode prejudicar sua produtividade devido a conexões e dependências interdepartamentais. Com relação a essa questão, a diferença entre os ecossistemas é explicada pela forma como as ameaças podem ser enfrentadas. Nos ecossistemas biológicos, os problemas são naturalmente resolvidos. Nas organizações hoteleiras, intervenções propositais e estratégicas são necessárias para superar dificuldades inesperadas.

Ainda sobre sua metáfora de analisar os ecossistemas organizacionais como biológicos, Mars, Bronstein e Lusch (2012) observam que laços ou mutualismos são interações que beneficiam espécies biológicas. No contexto da hospitalidade, o mutualismo consideraria como os atores veem esse fenômeno nas relações de troca de bens e serviços, nos quais ambas as partes (isto é, firmas e consumidores) podem lucrar. De certa forma, esse relacionamento mutualístico corresponde ao que Lusch e Vargo (2012) afirmam no primeiro axioma e premissa fundacional da LDS: "O serviço é a base fundamental da troca".

De acordo com esse pressuposto, pode-se observar que o principal objetivo das empresas hoteleiras é atender ou exceder as expectativas dos hóspedes para que eles possam reutilizar o serviço e difundir sua qualidade para terceiros e, como consequência, os hoteleiros recebam os benefícios de altas taxas de ocupação, independentemente da sazonalidade, harmonizando o axioma com o objetivo principal das organizações hoteleiras (Vargo \& Lusch, 2014).

A segunda premissa fundamental da lógica S-D afirma que a troca indireta mascara a base fundamental da troca. Inicialmente, nos hotéis, as trocas são essencialmente interpretadas como a troca de dinheiro pelos serviços de hospitalidade. No entanto, as trocas de hotéis também incluem experiências dos clientes na interação com funcionários e outros convidados. Por isso, o 
conhecimento que os hóspedes obtêm em suas trocas intangíveis é levado para outros momentos de suas vidas, como resultado, por exemplo, da prática de outro idioma, da degustação de novos alimentos, do conhecimento de outra cultura, etc. (Vargo \& Lusch, 2014).

A terceira premissa fundamental afirma que os bens são mecanismos de distribuição para a provisão de serviço. Assim, todos os itens oferecidos aos hóspedes em um hotel, desde uma caneta para preencher o formulário de check-in até as "comodidades" fornecidas no quarto do hotel, são veículos para promoção de serviços e podem ser uma fonte de vantagem competitiva na comparação com outros hotéis do mesmo padrão (Vargo \& Lusch, 2014).

No tocante à quarta premissa fundacional, recursos operantes são as principais fontes de vantagem competitiva. Assim, as habilidades e capacitações humanas dos atores da indústria hoteleira são os principais ativos das organizações. Consequentemente, os gestores devem investir regularmente na capacitação dos empregados dos hotéis, por exemplo, através do ensino à distância ou $e$ learning (Sanches \& Silva, 2011).

A quinta premissa fundacional afirma que todas as economias são economias de serviço. Como o serviço é a base da troca, o principal fenômeno econômico, todos os sistemas de troca e, consequentemente, todos as economias são na verdade economias de serviço. Um hotel é um sistema de prestação de serviços. Por isso, em todas ocasiões os hoteleiros devem ter uma visão holística da prestação de serviço, uma vez que a maximização de sua lucratividade depende do pleno uso dos recursos (Vargo \& Lusch, 2014).

De acordo com o segundo axioma e a sexta premissa fundamental, o cliente é sempre um cocriador de valor. Assim, na indústria hoteleira, os hóspedes devem ser vistos como atores ativos na busca, criação e consumo de valor, por meio de sua participação na prestação de serviços, ou seja, os gerentes de hotel devem analisar e aceitar as opiniões e sugestões relevantes dos hóspedes sobre serviços prestados. De fato, a cocriação de valor diz respeito ao processo pelo qual os clientes interagem com a empresa e geram suas próprias experiências, que constituem a base do valor e da inovação (Prahalad \& Ramaswamy, 2004a, b).

A sétima premissa fundacional afirma que uma empresa não pode entregar valor, mas apenas oferecer proposições de valor. No serviço hoteleiro, as proposições de valor podem ser expressas e tornadas tangíveis na qualidade dos bens e serviços entregues. Os gerentes de hotel devem prestar atenção ao modo como estão viabilizando a hospitalidade. A cocriação de valor é um processo dinâmico, interativo, não linear e muitas vezes não planejado, ou seja, emerge mais do pro- cesso de distribuição, o que implica na importância do valor de uso (Chathoth, et al. 2013).

A oitava premissa fundamental afirma que uma visão centrada no serviço é inerentemente orientada para o cliente e relacional. Assim, o processo de cocriação deve partir de uma visão centrada na empresa em direção a uma visão que é orientada para o cliente, e essa mudança deve ser destacada nas interações (Chathoth, et 
al. 2013). Nas empresas hoteleiras, os hoteleiros devem seguir essa premissa por meio do agrupamento de usuários de acordo com gênero, endereço, idade e outros dados pessoais e também por meio do monitoramento do comportamento dos usuários no acesso ao site do hotel. Todas as interações entre empresa e cliente devem ser gerenciadas para que o valor da empresa possa ser melhorado na perspectiva do cliente de tal forma que seu engajamento seja aumentado para atender às suas próprias necessidades específicas (Vargo \& Lusch, 2014; Chathoth, et al. 2013).

De acordo com o terceiro axioma e nona premissa fundacional, todos os atores econômicos e sociais são integradores de recursos. Isso leva a questões relativas aos processos envolvidos na interação entre a organização e o cliente com a finalidade de cocriar valor. Essas questões, segundo Roser et al. (2009), referem-se a quem estará envolvido, qual é o propósito da organização, onde a organização o realiza, quanto comprometimento é necessário e por quanto tempo. Assim, nas organizações hoteleiras, funcionários e clientes devem ser vistos como atores integradores de recursos. Tanto os colaboradores, direta e indiretamente, quanto os outros clientes influenciam o bem-estar e a qualidade da experiência dos hóspedes, portanto, seu comportamento deve ser gerenciado de maneira eficaz. De fato, como afirmam Hayes \& Ninemeier (2005), os objetivos organizacionais só podem ser alcançados se houver comprometimento e esforço das pessoas que fazem parte do hotel.

O quarto axioma (e décima premissa fundacional) afirma que o valor é sempre única e fenomenologicamente determinado pelo beneficiário. A LDS pressupõe que os recursos para criação de valor, os quais são cocriadores de valor em potencial, incluem empresas, clientes, fornecedores, governo, comunidade e outras partes interessadas (Chathoth, et al. 2013). Na indústria hoteleira, os hóspedes são os principais beneficiários. Eles estão se tornando cada vez mais exigentes. Assim, para atender às suas mudanças de comportamento dos clientes satisfazê-los, as empresas hoteleiras devem buscar novas formas de superar as expectativas dos clientes.

Por fim, o quinto axioma (e décima primeira premissa fundacional) destaca a importância das instituições e de seus arranjos para a criação de um ambiente e contexto que apoiem as trocas, a integração de recursos e a cocriação de valor. Por exemplo, as autoridades públicas devem garantir a segurança da população e do turismo, o que deve fomentar diretamente os negócios de hospitalidade. De fato, de acordo com Abdala (2017), apenas o Rio de Janeiro perdeu cerca de US $\$ 100$ milhões em receita do turismo nos quatro meses daquele ano devido à violência. Além disso, organizações independentes como 0 site Booking (http://www.booking.com), que intermedia o aluguel de quartos de hotel pela internet, desempenham um papel fundamental, porque equilibram oferta e demanda, e contribuem para garantir e aumentar a qualidade do serviço, através de mecanismos de avaliação e controle.

De acordo com as discussões do 56응 Congresso Nacional de Hotéis (CONOTEL- 
2014), existem quatro tipos de perfis de hóspedes, a saber: o afável, o analítico, o pragmático e o animado. Assim, um gerente do hotel deve estar preparado para atender aos hóspedes de qualquer uma dessas categorias. No evento, outro ponto destacado foi que os gerentes precisam ser estritamente cuidadosos com os detalhes da condução dos negócios para que possam encontrar um diferencial na prestação de serviços.

Segundo Chathoth (2013), as empresas podem colaborar com os clientes na cocriação de valor de duas maneiras. O primeiro diz respeito à criação de valor em uso (Kristensson et al., 2008, p. 476). Por exemplo, um hotel oferece aos hóspedes quartos de estilo futurista cuja cor pode ser alterada a seu critério durante sua estadia

A segunda maneira inclui inventividade compartilhada, codesign ou coprodução (Lusch, et al. 2007). Por exemplo, um hotel pode oferecer aos seus clientes um espaço virtual, no qual eles podem virtualmente visitar o hotel e coprojetar as instalações reais. Assim, em alguma medida, o hotel poderia adaptar-se às sugestões dos clientes, movendo-se em direção à experiência de cocriação.

Shaw et al. (2011) insistem em exortar os hotéis a implantar estratégias de cocriação com os clientes para inovar em bens e, principalmente, em serviços. Para Ottenbacher e Harrington (2010), as inovações de serviços podem aumentar a fidelidade dos clientes, impulsionando a venda de outros serviços de hotelaria, tornando os clientes mais satisfeitos, consequentemente, aumentando as receitas e os lucros.
A co-produção é outro construto usado na lógica $S-D$, intrinsecamente relacionado à co-criação de valor. Co-produção significa o engajamento dos clientes nos processos de criação por meio de inventividade compartilhada e co-design (Lusch et al., 2007). Envolve também sua participação nos processos de prestação de serviços. Assim, a co-produção depende da organização, porque é o processo do serviço ativado, pela mobilização de recursos e competências da empresa (Chathoth, et al. 2013).

Por outro lado, a cocriação está centrada na experiência do cliente, ou seja, está intimamente relacionada com o uso, valor em uso, durante a experiência de consumo, baseando-se na premissa de que o valor do serviço é singularmente avaliado pelo cliente (Lusch et al. 2007). Na cocriação, as empresas não tratam seus clientes como meros compradores de mercadorias, mas como parceiros na criação de experiências personalizadas, que acrescentam valor e prazer às suas vidas (Chathoth, et al. 2013).

Na verdade, a cocriação ultrapassa a customização de produtos e serviços para atender às necessidades do cliente. A diferença entre "cocriação" e "personalização" reside no grau de envolvimento dos consumidores em termos gerais, ou seja, "o cliente tem um papel menos ativo na personalização do que na cocriação" (Kristensson et al., 2008, p. 475). Em outras palavras, a principal distinção entre ambos os conceitos pode ser atribuída ao grau de engajamento do cliente. Diante do exposto, inferimos que os hoteleiros precisam inovar em seu conceito de hospitalidade, engajando os clientes no processo de criação do serviço. 
Confirmando esta conclusão, Prahalad e Ramaswamy (2004b) observam que o consumidor e a empresa estão intimamente envolvidos na co-criação de valor único para cada cliente, mas de tal forma que a empresa possa arcar com isso. Assim, os gerentes de hotel devem estar conscientes de que a vantagem competitiva pode ser alcançada na prestação de um serviço diferenciado (Lusch, Vargo, \& O 'Brien, 2007).

$A$ adoção de uma nova lógica de serviço significa que a organização deve passar por mudança radical, envolvendo a gestão da sua dinâmica ambiental interna e externa, bem como por mudanças de cultura, de filosofia e adaptação de fatores organizacionais - por exemplo, visão de liderança, estrutura, processos de trabalho, políticas de treinamento e de avaliação de desempenho e sistemas de informação e de comunicação (Okumus, 2003). Além disso, as mudanças de filosofia gerencial e a gestão de mudança de comportamento dos clientes devem ser orientadas por princípios do marketing social, com ênfase na mudança de comportamentos voluntários para o aumento da satisfação e qualidade de vida.

\section{CONSIDERAÇÕES FINAIS}

Como observado na rotina das empresas hoteleiras, os consumidores ainda são vistos como indivíduos separados do processo de prestação de serviço, ou seja, são percebidos como exógenos. Logo, é hora de os hoteleiros prestarem atenção e aderirem a uma lógica emergente - a Lógica Dominada por Serviço. Se assim o fizerem, as empresas hoteleiras desenvolverão uma rede de cola- boração $A 2 A$, que coproduzirá e cocriará valor para ganhos mútuos, através do desenvolvimento de práticas sociais e (re)construção de significado e de ação organizacional. Além disso, essas práticas também podem ajudar aos gestores a entender como o valor é cocriado e, mais amplamente, como os mercados podem ser cocriados através dessas práticas.

Como a cooperação dos atores na coprodução e cocriação de valor é central na LDS, hóspedes devem ser sempre tratados como cocriadores de valor e eventualmente como provedores de autoatendimento. Por causa isso, seu engajamento, disposição para o autosserviço e feedback são fundamentais para o desenvolvimento de propostas de valor na indústria hoteleira. Logo, as avaliações e sugestões dos hóspedes devem ser buscadas plena e sistematicamente.

Akaka, Vargo e Lusch (2013) observam que as mudanças culturais ocorrem pela interação entre empresas e consumidores, e coevoluem quando as práticas são estabelecidas e ocorrem interações entre múltiplos atores. Portanto, a cultura tornase o construto mais útil e relevante, devendo ser apreciada como fenômeno orgânico e dinâmico, que fomenta mudanças ou pode ser transformado.

O mundo vem mudando profunda e rapidamente. Por isso, Ritzer (2015) alerta para a necessidade de reavaliar urgentemente a hospitalidade e o setor de hospitalidade, em função da emergência de prossumidores, aumento do desemprego nessa indústria, como consequência da informatização, aumento do autosserviço e da con- 
centração de mercado. Alguns exemplos endossam as ideias de Ritzer: 1) alguns hotéis japoneses já usam robôs humanoides como atendentes (Portal G1, 2015); 2) com o crescimento da economia colaborativa, muitos turistas optam por se hospedar nas residências de outros turistas, num tipo de escambo, e muitos outros usam serviços como o Worldpackers, plataforma que possibilita a troca de trabalho por hospedagem em vários lugares do mundo.

Através desta reflexão, nós nos preocupamos em apresentar a nova lógica do marketing, bem como sugerir sua adoção para viabilizar o aumento da rentabilidade na indústria hoteleira através do aumento do bem-estar dos hóspedes. Em outras palavras, acreditamos que, à medida que os hóspedes são tratados como recursos importantes no processo da hospitalidade, eles poderão cocriar e coproduzir valor de serviço tendo em vista as suas próprias necessidades e desejos.

Para verificar o valor da aplicação da LDS no setor hoteleiro, são necessários e recomendados estudos empíricos, como a pesquisa feita por Ordanini e Parasuraman (2011). Com base em insights da LDS, os autores elaboram uma moldura conceitual para investigar os antecedentes e consequentes da inovação em serviço, posteriormente deduzindo hipóteses para explicar a inovação, em termos de volume e radicalidade, numa amostra de hotéis de luxo. Fundamentados na LDS, Ordanini e Parasuraman (2011) mostram a importância do engajamento de clientes e empregados de linha de frente, da orientação para o mercado, da colaboração com parceiros comerci- ais e do uso de mecanismo de integração de conhecimentos para explicar inovações bem-sucedidas nos hotéis. Tais resultados são promissores e atestam a importância de uma nova lógica para entender as trocas numa sociedade estetizada e hiper-real (Veiga, Urdan, \& Matos, 2014).

\section{REFERÊNCIAS}

Achrol, R. S.; Kotler, P. (2012). Frontiers of the marketing paradigm in the third millennium. Journal of the Academy of Marketing Science. v. 40, p. 35-52.

Abdala, V. (2017). Por causa da violência, turismo no Rio perde R\$ 320 milhões em quatro meses. Agência Brasil. Disponível em: <http://agenciabrasil.ebc.com.br/economia/noticia/2017-

07/por-causa-da-violencia-turismo-no-rio-de-janeiro-perde-r-320-milhoes-em-4> Acesso em: 02 de fevereiro de 2018.

AKAKA, M. A.; VARGO, S. L.; LUSCH, R. F. (2013). The Complexity of Context: A Service Ecosystems Approach for International Marketing. Journal of International Marketing. v. 21, n. 4, p. 1-20.

AXELROD, R. (1984). The Evolution of Cooperation. New York: Basic Books.

CABIDDU, F; LUI, T. W.; PICCOLI, G. (2013). Managing value co-creation in the tourism industry. Annals of Tourism Research, 42, 86-107.

Castelli, G. (1992). Administração Hoteleira. Caxias do Sul: EDUCS.

Chathoth, Prakash et al. (2013). Co-production versus co-creation: A process based continuum in the hotel service context. International Journal of Hospitality Management, v. 32, p. 11-20. 
Conotel. (2014). Exigências dos hóspedes são discutidas no 56 Conotel. Disponível em: <http://www.revistahoteis.com.br/materias/1Aconteceu/15342-Exigencias-do-hospedes-saodiscutidas-no-56o-Conotel> Acesso em: 04 de dezembro de 2014.

FitzPATRICK, M.; DAVEY, J.; MulleR, L.: DAVEY, H. (2013). Value-creating assets in tourism management: Applying marketing's service-dominant logic in the hotel industry. Tourism Management,36, 86-98.

GrönRoOS, C.; Voima, P. (2013). Critical service logic: making sense of value creation and co-creation. Journal of Academy of Marketing Science. v. 41 , p. $133-150$.

Hayes, D. K.; Ninemeier, J. D. (2005). Gestão de Operações Hoteleiras. São Paulo: Pearson Prentice Hall.

HUNT, S. D. (1999). A general theory of competition: Resources, competences, productivity, economic growth. Sage Publications.

Kristensson, P., Matthing, J., Johansson, N., (2008). Key strategies for the successful involvement of customers in the co-creation of new technology-based services. International Journal of Service Industry Management 19 (4), p. 474-491.

Lusch, R. F.; Vargo, S. L. (2006). Service-Dominant Logic: reaction, reflections and refinements. Marketing Theory, v. 6, n.3, p. 281-288.

Lusch, R. F.; Vargo, S. L. (2014). Service-Dominant Logic: Premises, Perspectives, Possibilities. Cambridge: Cambridge University Press.

Lusch, R. F.; Vargo, S. L.; O'brien, M. (2007). Competing through service: Insights from service- dominant logic. Journal of Retailing, v. 83, n. 1, p. 5-18.

Mars, M. M.; Bronstein, J. L.; Lusch, R. F. (2012). The value of a metaphor: Organizations and ecosystems. Organizational Dynamics, v. 41, n. 4, p. 271-280.

Morosan, C.; Defranco, A. (2016). Co-creating value in hotels using mobile devices: A conceptual model with empirical validation. International Journal of Hospitality Management, 52, 131-142.

Ng, I.; Badinelli, R.; Polese, F.; Di Nauta, P.; Löbler, H., Halliday, S.S-D. (2012). Logic Research Directions and Opportunities: The Perspective of Systems, Complexity and Engineering. Marketing Theory, v.12, n.2, p. 213-217.

Okumus, F., (2003). A framework to implement strategies in organizations. Management Decision, p. 871-882.

ORdaninI, A., \& Parasuraman, A. (2011). Service innovation viewed through a service-dominant logic lens: a conceptual framework and empirical analysis. Journal of Service Research, 14(1), 3-23.

Ottenbacher, M.C., Harrington, R.J., (2010). Strategies for achieving success for innovative versus incremental new services. The Journal of Services Marketing, p. 3-15.

Portal G1 (2015). Hotel de baixo custo terá robôs como funcionários no Japão. Disponível em: $<$ http://g1.globo.com/turismo-e-viagem/noticia/2015/07/hotel-de-baixo-custo-tera-roboscomo-funcionarios-no-japao.html> Acesso em: 02 de fevereiro de 2018.

Prahalad, C.K., Ramaswamy, V., (2004a). The Future of Competition: Co-creating Unique 
Value with Customers. Harvard Business, School Press, Boston, MA.

Prahalad, C.K., Ramaswamy, V., (2004b). Cocreation experiences: the next practice in value creation. Journal of Interactive Marketing, p. 514.

Prahalad, C. K.; Ramaswamy, V. (2004). O Futuro da Competição: como desenvolver diferenciais inovadores em parceria com os clientes. Rio de Janeiro: Elsevier.

RITZER, G. (2015). Hospitalidade e prossumerização. Revista Hospitalidade, p. 12-41.

Roser, T., Samson, A., Humphreys, P., (2009). Cruz-Valdivieso, E., Co-creation: New Pathways to Value: An Overview. Promise/LSE Enterprise, London.

Sanches, P. L. B.; Silva, A. B. (2011). O Outro Lado da Moeda: a aprendizagem corporativa de gerentes de instituições financeiras. Anais da ANPAD: EnGPR.

Shaw, G., Bailey, A., Williams, A. (2011). Aspects of service-dominant logic and its implications for tourism management: examples from the hotel industry. Tourism Management, p. 207-214.

Vargo, S. L.; Akaka, M. A. (2012). Value Creation and Service Systems (Re)Formation: A Service Ecosystems View. Service Science. v.4, n.3.

Vargo, S. L.; Lusch, R. F. (2004). Evolving to a New Dominant Logic for Marketing. Journal of Marketing, v. 68, p. 1-17.
VeIGA, R. T.; URdAN, A. T.; \& MATOS, C. A. D. (2014). Estetização do marketing. Revista de Administração de Empresas, 54(2), 232-238.

Zeithaml, V. A. (1981). How Consumer Evaluation Processes Differ between Goods and Services. In: Lovelock, C. Services Marketing. (2 ${ }^{\mathrm{a}}$ ed.) Upper Saddle River, New Jersey: Prentice Hall

\section{Informações dos Autores}

\section{Jefferson Oliveira da Silva-Lacerda}

Professor do Curso de Hospitalidade da Escola Cidadã Integral Técnica Presidente João Goulart (ECIT João Pessoa-PB). Doutorando em Administração (CEPEAD/UFMG). Mestre em Administração (PPGA/UFPB). Bacharel em Hotelaria e Licenciado em Letras - Universidade Federal da Paraíba (UFPB).

E-mail: jeffersoncantalice3@gmail.com

ORCID: 0000-0003-4927-1242

\section{Marcela Nunes de Castro}

Consultora em Estratégia e Gestão Empresarial. MBA em Gerenciamento de Projetos pela IBS - Fundação Getúlio Vargas. Graduação em Ciências Econômicas (UFMG).

E-mail: marceladecastro@gmail.com

ORCID: 0000-0003-4483-1941

\section{Ricardo Teixeira Veiga}

Professor Associado da Universidade Federal de Minas Gerais (UFMG). Coordenador do Núcleo de Estatística e Ciências Comportamentais (NECC). Revisor das revistas FACE, RAE, RAC, BAR e RAHIS. Doutor em Administração (UFMG). Mestre em Administração (UFMG). Graduado em Ciência da Computação (UFMG).

E-mail: ricardo.necc@gmail.com

ORCID: 0000-0001-5467-0972 